\title{
Model and mechanism of carbon nanotube stabilization with plasticizer
}

\author{
Svetlana Samchenko ${ }^{1}$, Irina Kozlova $^{1 *}$ and Olga Zemskova ${ }^{1}$ \\ ${ }^{1}$ Moscow State University of Civil Engineering, Yaroslavskoye shosse, 26, 129337, Moscow, Russia
}

\begin{abstract}
Mechanism of stabilization of carbon nanotube (CNT) water suspension with plasticizer based on sulfated naphthalene formaldehyde resins is proposed in this article. CNT stabilization is achieved at the expense of fixing plasticizer group on the nanoparticle surface. Nonpolar part of plasticizer provides the formation of high-viscosity streak between CNTs particles and dispersion medium, and polar part provides the formation of double electrical layer, that supports formation of CNT micelle. Model of carbon nanotube micelle is described. It is determined that the conducting of ultrasonic dispersion of CNTs water suspensions with plasticizer based on sulfated naphthalene formaldehyde resins provides stability of CNTs suspensions for 7 and more days. Optimal options of ultrasonic effect are identified. It is shown that CNT suspension stabilized with sulfated naphthalene formaldehyde evenly apportion in volume of cement system in conclusion of the adding them to composition of cement paste. This distribution helps with obtaining cement stone with high exploitative properties.
\end{abstract}

\section{Introduction}

Nowadays the world scientific community pays a lot of attention to the applying of carbon nanotubes (CNTs) in the compositions of building composite materials. We can find many articles in different magazines and discussions from forums [1-8]. However, CNT does not get wide usage on an industrial scale because of the complexity of entering them into cement system and evenly allocation in its volume $[9,10]$.

One of the perspective method of CNTs adding to cement composition is the applying of stabilized CNTs suspensions both in water [11] and dispersion water-polymeric [12-14] mediums by acoustic dispersion [9]. Efficiency of influence on dispersions systems stabilization with ultrasonic [15,16] and different physicals options [17] are paid a lot of attention from the industrial scale point of view.

Usage nanosized modifiers like suspension for making advanced building materials with given functional properties needs to research physicals and chemicals properties in details.

The main aim of this article is study aggregative and sedimentary stability CNTs suspensions with plasticizer based on sulfated naphthalene formaldehyde resins at ultrasonic effect, determination of kinetic addictions of coagulation, description of

\footnotetext{
*Corresponding author: vskanhva@mail.ru
} 
suspension stabilization models and mechanisms according to the modern theory and definition of CNTs applying in the form of suspensions possibility for Portland cement modifying.

\section{Experimental}

\subsection{Materials and experimental procedure}

The object of research is Portland cement, carbon nanotube and plasticizer. Portland cement have been obtained by co-grinding clinker and 5\% natural gypsum in the laboratory mill up to sieve residue was $\mathrm{R}_{008}=6 \%$. The table 1 shows the chemical and mineralogical composition of clinker.

Carbon nanotubes have been obtained by method of low-temperature catalytic pyrolysis of hydrocarbons. They have following characteristics: external diameter $-20-150 \mathrm{~nm}$, internal diameter $-8-10 \mathrm{~nm}$ and length $-3-7 \mu \mathrm{m}$. Concentration of CNT in suspension is $0.25-1.0 \mathrm{~g} / 1$.

The plasticizer based on sulfated naphthalene formaldehyde resins is used as a surfaceactive substance. His molecules have nonpolar and polar parts. Polar groups of sulfated naphthalene formaldehyde (R-SO3-) are formed with SO3- anions. Plasticizer is entered as suspension in an amount of 0.1-5 g/l.

Acoustic dispersion of suspension is done at the frequency of ultrasonic vibrations -44 $\mathrm{kHz}$, at the temperature of $25 \pm 2 \mathrm{oC}$ and time of the dispersion - 10-30 min. Stationary temperature of the dispersion have been reached with thermostating of the suspensions.

Table 1. Portland cement and its major constituent phases.

\begin{tabular}{|c|c|c|c|}
\hline \multicolumn{2}{|c|}{$\begin{array}{c}\text { Chemical Analyses of Portland cement } \\
\text { clinker, \% }\end{array}$} & \multicolumn{2}{|c|}{$\begin{array}{c}\text { Mineralogical composition of clinker } \\
\text { (major constituent phases, } \% \text { ) }\end{array}$} \\
\hline $\mathrm{CaO}$ & 63.89 & \multirow{2}{*}{ Alite } & \multirow{2}{*}{63} \\
\hline $\mathrm{SiO}_{2}$ & 20.63 & & \\
\hline $\mathrm{Al}_{2} \mathrm{O}_{3}$ & 5.62 & \multirow{2}{*}{ Belite } & \multirow{2}{*}{11} \\
\hline $\mathrm{Fe}_{2} \mathrm{O}_{3}$ & 5.15 & & \\
\hline $\mathrm{MgO}$ & 3.68 & \multirow{2}{*}{ The aluminate phase } & \multirow{2}{*}{6} \\
\hline $\mathrm{SO}_{3}$ & 0.59 & & \\
\hline $\mathrm{R}_{2} \mathrm{O}$ & 1.36 & The ferrite phase & 15 \\
\hline
\end{tabular}

Cement samples for researches have been made with the applying of stabilized CNTs suspensions in water and dispersion water-polymeric mediums to Portland cement. There is used both as fresh and stored for 30 days suspensions. Cement strength have been determined by national standard GOST 30744-2001. Porosity of cement stone have been determined by the method of saturation samples with inert liquid.

The produce of hydration, structure formation and properties of cement stone have been determined by X-ray analyze and electron microscopy. X-ray analysis is done with diffractometer with copper anticathode $(\mathrm{Cu}$ anode $\lambda \mathrm{K} \alpha 1=1.54056 \AA ; 40 \mathrm{~mA}$ and $40 \mathrm{kV})$. The acquisition range was from $5^{\circ}$ to $60^{\circ} 2 \theta$ in $0.02^{\circ} 2 \theta$ steps with integration at the rate of $50 \mathrm{~s}$ per step. The identification of minerals was realized by using data base JCPDS.

Content of hydrated phases has been determined by quantitative phase analysis with using of internal standard method. When use this method, it is added the accurately known amount of reference substance to test sample. Fluorite $\left(\mathrm{CaF}_{2}\right)$ has been used as reference substance because of his intensive lines with $d=0.316 \mathrm{~nm}\left(2 \theta=28^{\circ} 10^{\prime}\right)$ are close to analytical lines of cement minerals. 


\section{Results and discussion}

\subsection{Stabilization of CNT suspension}

The plasticizer is used as a stabilizer of CNT water suspension. It is added to water suspension at the amount of following ratio: from 0.1 to $1.0 \%$ with step of $0.2 \%$; from 1.0 to $2.5 \%$ with step of $0.5 \%$; from 3 to $5 \%$ with step of $1 \%$. Index of stabilizer protective action is considered with minimal amount of substance, which needs to stabilize volume sol unit. It calls protective number. It can be count by this formula:

$$
\mathrm{S}=\left(\mathrm{C}_{\mathrm{ct}} \times \mathrm{V}_{\mathrm{z}}\right) / \mathrm{V}
$$

where $\mathrm{S}$ - protective number, $\mathrm{g} / \mathrm{l} ; \mathrm{C}_{\mathrm{ct}}$ - concentration of stabilizer, $\mathrm{g} / \mathrm{l} ; \mathrm{V}_{\mathrm{z}}-$ volume of stabilizer solution, $\mathrm{ml} ; \mathrm{V}$ - volume of suspension, $\mathrm{ml}$.

The table 2 shows the results of counting.

Table 2. Aggregative stability of CNT water-polymeric suspension.

\begin{tabular}{|l|c|c|c|c|c|c|c|c|c|c|c|c|}
\hline $\begin{array}{c}\text { Concentration } \\
\text { of stabilizer, } \\
\mathrm{g} / \mathrm{l}\end{array}$ & 0.1 & 0.2 & 0.4 & 0.6 & 0.8 & 1.0 & 1.5 & 2.0 & 2.5 & 3.0 & 4.0 & 5.0 \\
\hline $\begin{array}{l}\text { Protective } \\
\text { number of } \\
\text { suspension, } \\
* 10^{-3} \mathrm{~g} / \mathrm{l}\end{array}$ & 0.01 & 0.04 & 0.12 & 0.3 & 0.56 & 0.8 & 1.95 & 3.4 & 5.25 & 7.5 & 13.2 & 21 \\
\hline $\begin{array}{l}\text { Aggregative } \\
\text { stability of } \\
\text { CNT } \\
\text { suspension, } \\
\text { days }\end{array}$ & 1 & 1 & 1 & 1 & 1 & 1 & 2 & 2 & 2 & 7 & $>7$ & $>7$ \\
\hline
\end{tabular}

Stabilized action of superplasticizer can be evaluated according to the information from the table. For having stability after 7 days it is needed to add plasticizer at an amount of 3-5 $\mathrm{g} / \mathrm{l}$. Suspension stays stability after 30 and more days on conclusion of the adding amount of $5 \mathrm{~g} / \mathrm{l}$.

\subsection{Aggregative and sedimentary stability of CNTs suspensions after acoustic impact}

Separation of fine-grained powders in water and water-polymeric medium has been done with ultrasonic dispersion. Abrupt changes of pressure in dispersion medium, that entail disconnection of particle aggregates, arise because of fluid-passing acoustic wave and cavitation (formation of gas bubbles in a liquid). However, in this case dispersion medium warms up. The temperature increases to $50{ }^{\circ} \mathrm{C}$ and subsidence rate of CNT increases (fig. 1), but aggregative and sedimentary stability of CNT suspension decreases. 


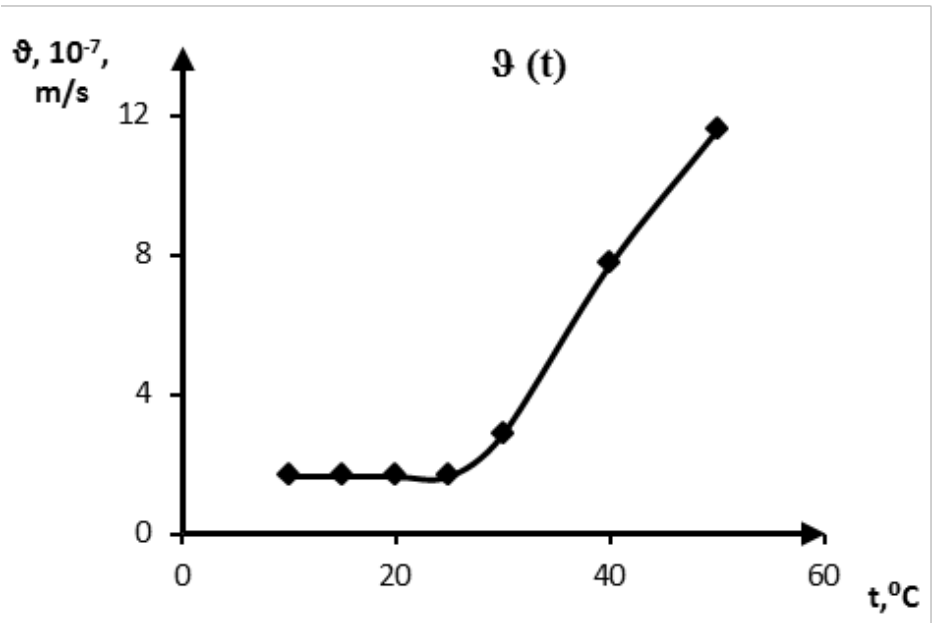

Fig. 1. Ratio of subsidence rate of CNT and the temperature of dispersion.

In dispersion medium at the increase of temperature to $50{ }^{\circ} \mathrm{C}$ two competing processes occur at the same time. On the first side, Brownian motion is intensified, that provides homogeneity of CNT suspension and, as a result, sedimentary stability of nanoparticles. On the other side, frequent collision of CNT particles provides the process of coagulation, that leads to enlargement of particle aggregates and gains sedimentation. There is an imbalance in the system, that has a negative effect on the CNT division with ultrasonic impact and on their stabilization both in water (fig. 2a) and water-polymeric (fig. 2b) mediums, that is consistent with researches by this authors $[16,17]$.

a.

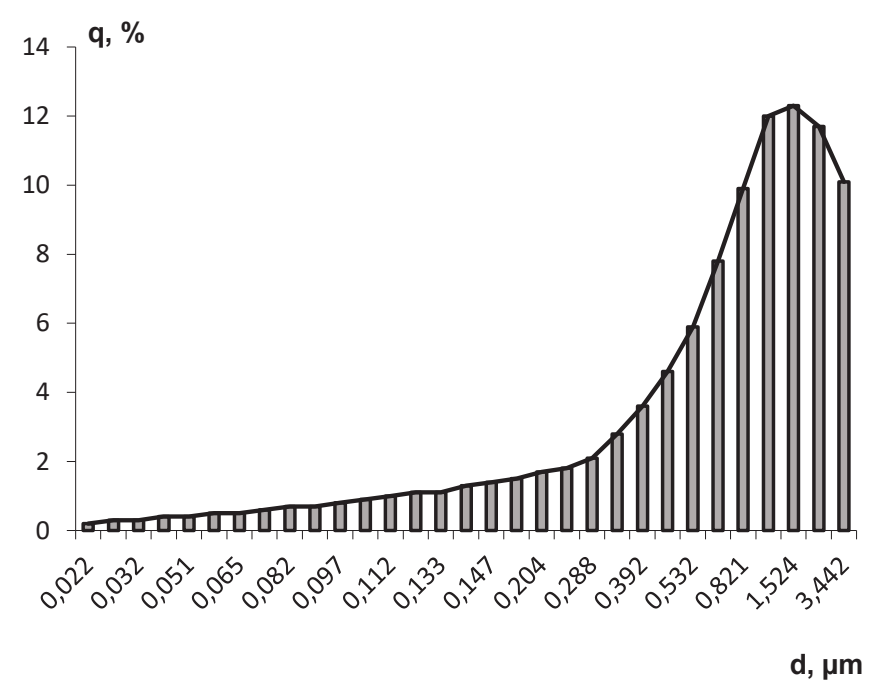




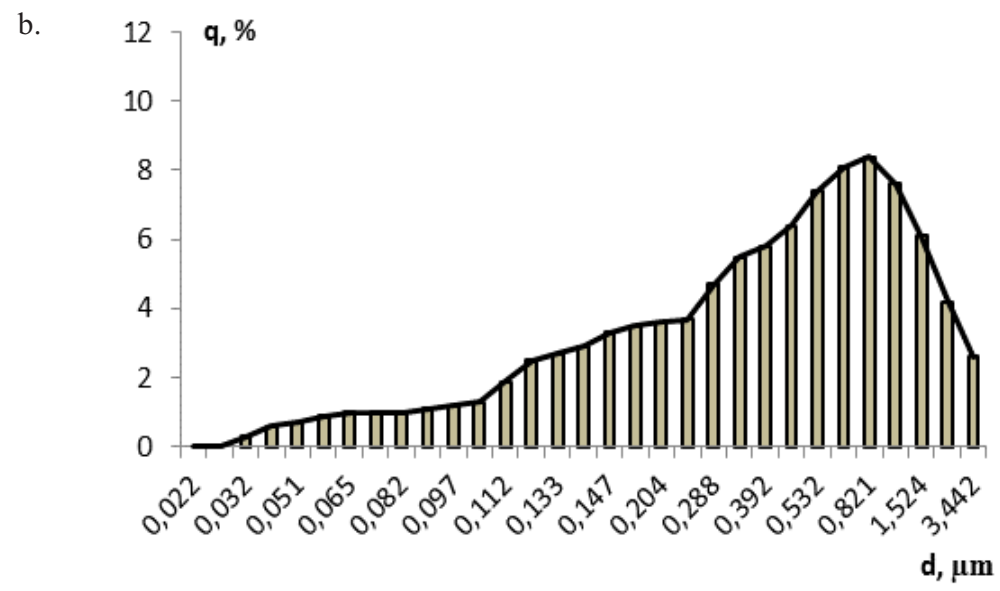

Fig. 2. Schedule of CNT distribution at the temperature $50{ }^{\circ} \mathrm{C}$ in water (a) and water-polymeric (b) dispersion mediums.

Thermostating of the suspensions at the temperature of $25 \pm 2{ }^{\circ} \mathrm{C}$ has been done for prevention influence of high temperature on the process of dispersion. Stationary temperature allows to get aggregative and sedimentary stabilized CNT suspensions (fig. 3)

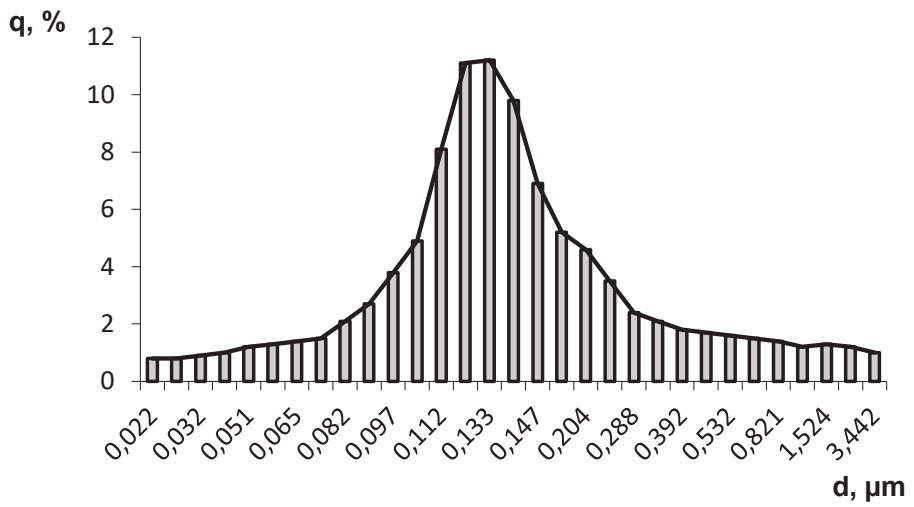

Fig. 3. Schedule of CNT distribution at the stationary temperature $25 \mathrm{oC}$ in water-polymeric medium.

\subsection{Model of carbon nanotube micelle}

Stabilized action of plasticizer based on sulfated naphthalene formaldehyde resins can be explained with formation of micelles. Molecules of plasticizer, that has non-polar and polar parts, lyophilize CNT surface, adsorb on it and form oriented layer, where hydrocarbon radicals of the main chain are inward (to CNT) and polar groups of sulfated naphthalene formaldehyde ( $\mathrm{R}^{-\mathrm{SO}^{-}}$) - to water dipoles. In this case surface tension is minimal and double electrical layer is formed [18,19], that in couple with dispersion phase is CNT micelle (fig. 4). 


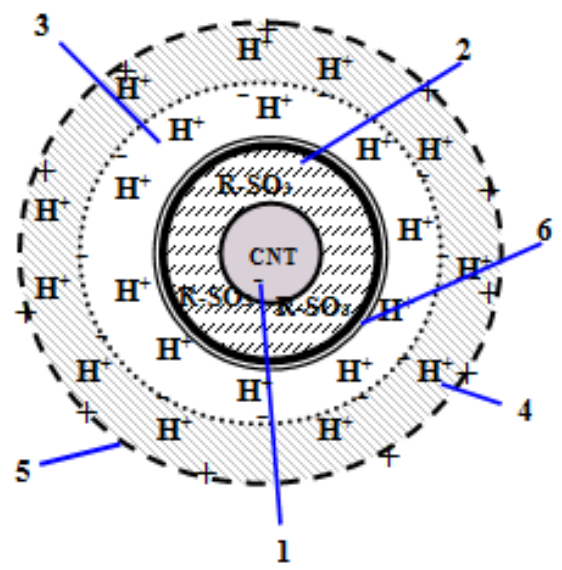

Fig. 4. The model of structure of micelle of carbon nanotubes, which stabilized sulfated naphthalene formaldehyde, where: 1 - aggregative of CNT; 2 - layer of potential-determining ions; 3 - counter ions of a dense part of a double electric layer; 4 - counter ions of diffuse layer; 5 - CNT micelle; 6 gel-like pellicle of the main chain radicals $\mathrm{R}-\mathrm{SO}^{-}$.

Internal part of the micelle (5) consists of aggregate having m particles of CNTs (1). Potential-determining ions nR-SO3- (2) are located on the surface of this aggregate, that in couple compose the core of micelle. The core with counter ions $(n-x) \mathrm{H}+$, which are in a dense part of a double electric layer (3), form the granule, that has negative charge. The granule is surrounded with remaining counter ions $\mathrm{x} \mathrm{H}+$ of diffuse layer (4), that are components of electrically neutral micelle.

\subsection{Mechanism of carbon nanotube stabilization with plasticizer}

CNT stabilization is achieved at the expense of fixing plasticizer group on the nanoparticle surface. Nonpolar part of plasticizer provides the formation of high-viscosity streak between CNTs particles and dispersion medium, and polar part provides the formation of double electrical layer, that supports formation of CNT micelle.

Molecules of sulfated naphthalene formaldehyde form the gel-like pellicle of the main chain radicals (6) on the surface layer of CNTs. This pellicle has high structural-mechanical and hydrodynamic properties, that provides stabilization of CNT. They have mechanical strength, elastic properties and block coalescence and fusion of particles. That explains mechanical factor of aggregative stability [20,21].

Stabilizing effect of the plasticizer on the CNT suspension is reached due to electrostatic, adsorption-solvate and structural-mechanical stability factors. Adsorptionsolvate and electrostatic stability factors are components of the structural-mechanical factor and contribute to the formation of elastic surface layers, thus, supplementing the action of the structural-mechanical factor. In this regard, we can assume that the stabilization of the system "CNT-water" with sulfated naphthalene formaldehyde is provided due to the structural-mechanical factor of aggregative stability.

\subsection{Study of the suspensions effect on the cement properties}

In first time, increase mobility of cement paste are shown on conclusion of adding the stabilized CNTs suspensions with lyophilized surface, and the water requirement of cement 
decreases and cement setting processes slow down (Table 3). The higher the concentration of CNTs in a cement system, the more it grasps more slowly.

Table 3. The properties of cement paste of nanomodified samples

\begin{tabular}{|l|c|c|}
\hline \multicolumn{1}{|c|}{ The cement composition } & $\begin{array}{c}\text { Normal density, } \\
\%\end{array}$ & $\begin{array}{c}\text { The starts of grasping } \\
\text { cement paste, } \\
\text { min }\end{array}$ \\
\hline PC & 27,0 & 190 \\
\hline PC with CNT $(0,25 \mathrm{~g} / 1)$ & 27,0 & 195 \\
\hline PC with CNT $(0,5 \mathrm{~g} / 1)$ & 27,0 & 202 \\
\hline PC with CNT $(1 \mathrm{~g} / 1)$ & 27,0 & 210 \\
\hline PC with SP $(5 \mathrm{~g} / 1)$ & 23,0 & 225 \\
\hline PC with CNT $(0,25 \mathrm{~g} / 1)$ and with SP $(5 \mathrm{~g} / 1)$ & 22,0 & 235 \\
\hline PC with CNT $(0,5 \mathrm{~g} / 1)$ and with SP $(5 \mathrm{~g} / 1)$ & 22,0 & 238 \\
\hline PC with CNT $(1 \mathrm{~g} / 1)$ and with SP $(5 \mathrm{~g} / 1)$ & 22,0 & 245 \\
\hline
\end{tabular}

Such properties of cement paste can be explained by mutual repulsion of negatively charged particles of stabilized CNTs and hydrated cement grains (fig. 5a). The particles of stabilized CNTs get negative charge because of formation oriented layer of anionic plasticizer on their surface. Particles of cement have a negative charge due to the hydrolysis process on the surface of cement grains.

While passing the hydrolysis process, the capsule of hydrated neoplasms on the surface of cement particles is charged positively. It is happened because of the accumulation of ions $\mathrm{Ca}^{2+}$ in it. Stabilized CNTs with their anionic part are attracted to hydrated cement particles, thereby reinforcing the cement array (fig. 5b).

With further hydration, the reinforcing carcass overgrown with crystalline hydrates, which determines the formation of a dense and durable cement stone. The table 4 shows the results of determining the strength and porosity of Portland cement.

Table 4. Strength and porosity of Portland cement.

\begin{tabular}{|l|c|c|c|c|}
\hline \multirow{2}{*}{ Portland cement } & \multicolumn{2}{|c|}{ Strength, MPa } & \multicolumn{2}{c|}{ Porosity,\% } \\
\cline { 2 - 5 } & 1 day & 28 days & 1 day & 28 days \\
\hline PC & 18,7 & 62,8 & 35,62 & 18,83 \\
\hline PC with CNT $(0,25 \mathrm{~g} / 1)$ & 27,5 & 65,3 & 31,76 & 15,77 \\
\hline PC with CNT $(0,5 \mathrm{~g} / 1)$ & 26,3 & 65,5 & 31,97 & 15,91 \\
\hline PC with CNT $(1 \mathrm{~g} / 1)$ & 23,5 & 68,3 & 32,04 & 15,96 \\
\hline PC with SP $(5 \mathrm{~g} / 1)$ & 18,1 & 71,1 & 32,38 & 16,65 \\
\hline $\begin{array}{l}\text { PC with CNT }(0,25 \mathrm{~g} / 1) \text { and with } \\
\text { SP }(\mathrm{g} / \mathrm{l})\end{array}$ & 27,7 & 73,8 & 30,52 & 15,58 \\
\hline $\begin{array}{l}\text { PC with CNT }(0,5 \mathrm{~g} / 1) \text { and with SP } \\
(5 \mathrm{~g} / 1)\end{array}$ & 26,5 & 73,3 & 31,05 & 15,72 \\
\hline $\begin{array}{l}\text { PC with CNT }(1 \mathrm{~g} / 1) \text { and with SP } \\
(5 \mathrm{~g} / \mathrm{l})\end{array}$ & 25,7 & 72,2 & 31,40 & 15,79 \\
\hline
\end{tabular}

This information shows that strength of cement stone increase at 1 day on $37 \%$, at 28 days - on $15 \%$, and porosity decrease at 1 day on $13 \%$, at 28 days - on $15 \%$. 
a.

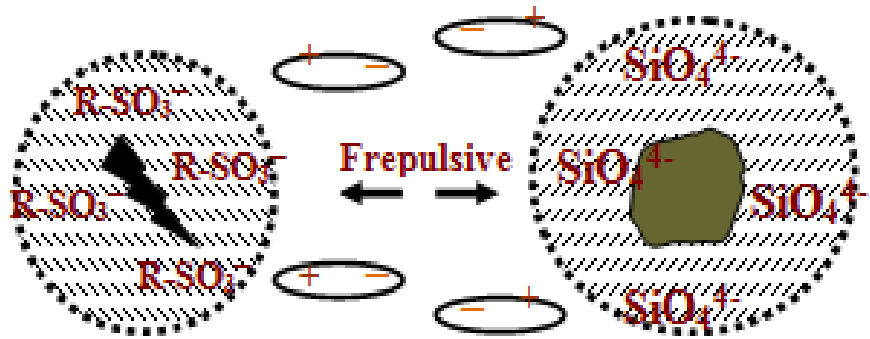

b.

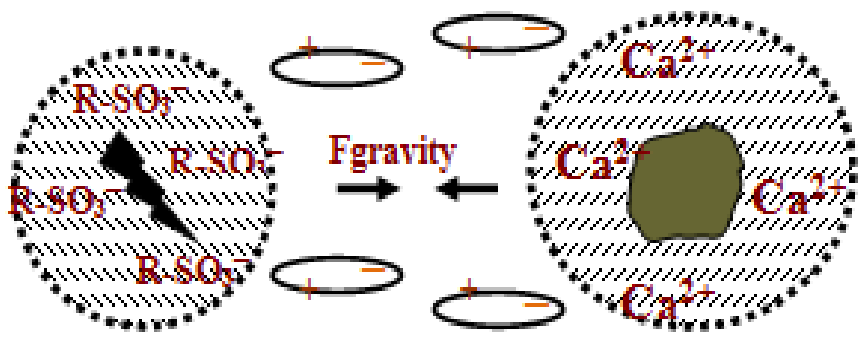

Fig. 5. The mechanism of interaction of stabilized CNTs with cement: a - stabilized CNT particle and particle of cement have a negative charge; $b$ - stabilized CNT particle and particle of cement have a positive charge.

\subsection{Study of the cement stone structure}

The quantitative composition of the cement stone with CNTs was determined by X-ray analysis. The results are shown at the table 5 .

Table 5. The quantitative composition of the cement stone with CNTs.

\begin{tabular}{|l|c|c|c|c|c|c|}
\hline \multirow{2}{*}{$\begin{array}{l}\text { Name of } \\
\text { mineral }\end{array}$} & \multicolumn{5}{|c|}{ The quantitative phase content,\% } \\
\cline { 2 - 7 } & PC & $\begin{array}{c}\text { PC with } \\
\text { CNT }\end{array}$ & $\begin{array}{c}\text { PC with } \\
\text { CNT and } \\
\text { with SP }\end{array}$ & PC & $\begin{array}{c}\text { PC with } \\
\text { CNT }\end{array}$ & $\begin{array}{c}\text { PC with } \\
\text { CNT and } \\
\text { with SP }\end{array}$ \\
\hline Alite & 47,25 & 44,35 & 42,07 & 15,86 & 13,81 & 10,25 \\
\hline Belite & 10,48 & 10,18 & 10,05 & 8,70 & 7,74 & 5,47 \\
\hline $\begin{array}{l}\text { The } \\
\text { aluminate } \\
\text { phase }\end{array}$ & 2,15 & 1,89 & 1,75 & - & - & - \\
\hline $\begin{array}{l}\text { The ferrite } \\
\text { phase }\end{array}$ & 5,55 & 5,32 & 5,15 & - & - & - \\
\hline $\mathrm{Ca}(\mathrm{OH})_{2}$ & 8,60 & 9,42 & 10,05 & 15,49 & 15,75 & 16,06 \\
\hline $\mathrm{CaCO} 3$ & - & - & - & 1,27 & 0,34 & 0,29 \\
\hline $\begin{array}{l}\mathrm{AFt} \\
\text { phases }\end{array}$ & 0,29 & 0,29 & 0,27 & - & - & - \\
\hline $\mathrm{C}-\mathrm{S}-\mathrm{H}$ & 25,68 & 28,55 & 30,66 & 58,68 & 62,36 & 67,93 \\
\hline
\end{tabular}

This results help to estimate the dynamic growth of neoplasms and changes in the crystalline structure of cement stone. For 1 day of hardening, the content of calcium hydrosilicates $(\mathrm{C}-\mathrm{S}-\mathrm{H})$ and the amount of $\mathrm{C}-\mathrm{S}-\mathrm{H}$ in cement stone when water and waterpolymer suspensions of CNTs are added to the cement composition increase compared to the zero-additive cement. Such trend persists to 28 days of hardening. 
Electron microscopic analyses of the samples shows that when adding to cement both pure CNTs and CNTs in combination with a superplasticizer, the formation of the cement stone structure takes place without the formation of large portlandite fields, which are characteristic for the structure of the Portland cement stone. The structure of the cement stone is presented poorly crystallized scaly calcium hydrosilicates (fig. 6).

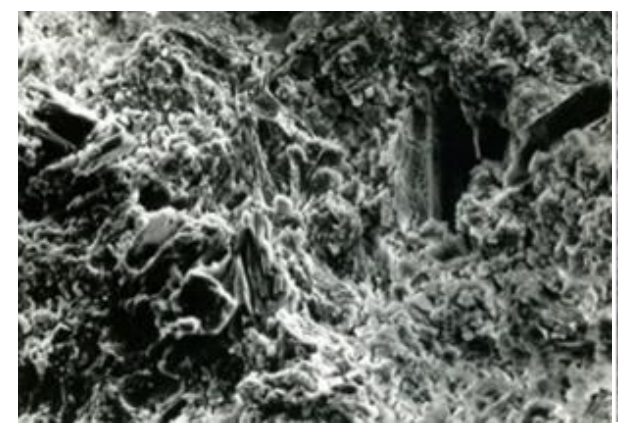

a.

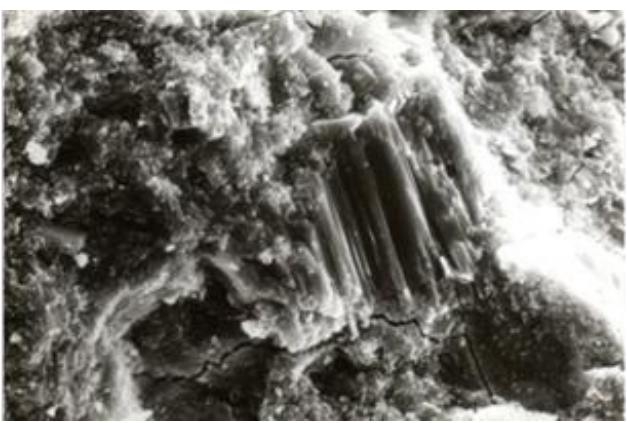

b.

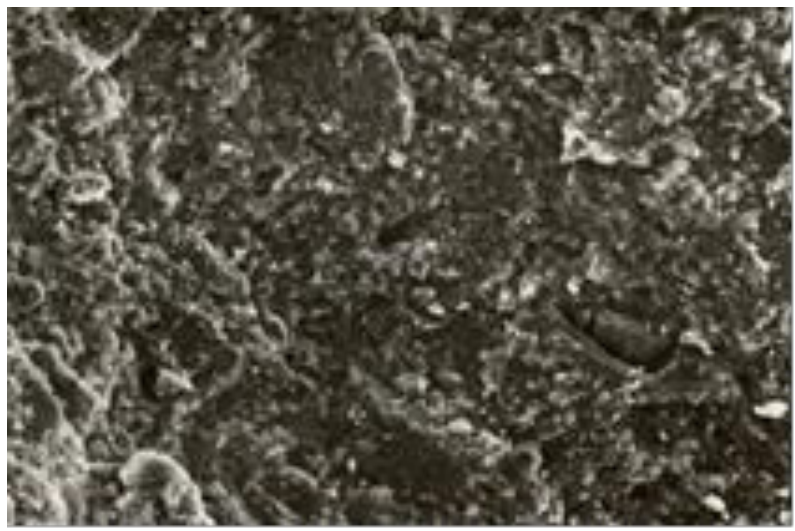

c.

Fig. 6. SEM images of hydrated samples after 28 days, where: a - PC; b - PC with CNT; c -PC with CNT and with SP.

Formation of this structure is due to the fact that calcium hydroxide, adsorbed on the surface of stabilized CNTs, does not crystallize into individual portlandite fields, but interacts with the crystalline hydrates of the solidifying system and binds to calcium hydrosilicates, which envelop the CNTs and bind the individual phases in the composition.

\section{Conclusion}

The study of the mechanism of CNT stabilization with sulfated naphthalene formaldehyde from the position of colloid chemistry makes it possible to explain the aggregative stability of water-polymeric CNT suspensions due to the formation of micelles $\left\{(\mathrm{CNT}) \mathrm{m} \mathrm{nR-SO3}{ }^{-}\right.$ (n-x) $\mathrm{H}+\}^{-} \cdot \mathrm{xH}+$. Ultrasonic impact on CNTs suspensions provides their aggregative stability due to the structural-mechanical factor. Stabilization of CNT suspension with sulfated naphthalene formaldehyde resins evenly apportion in volume of cement paste. The influence of stabilized CNTs on formation the cement stone structure allows to consider them like primary nanomaterials, that contain primary hydrated phases. Further formation of C-S-H around CNTs forms a cement stone with improved physical-mechanical and 
structural characteristics. The possibility of using CNTs like suspensions for modifying Portland cement is shown.

\section{References}

1. G.I. Jakovlev, G.N. Pervushin, A. Korzhenko, A.F. Buryanov, J. Kerene, I.S. Maeva, D.R. Hazeev, I.A. Pudov, S.A. Senkov, Stroitel'nye materialy 2, 25-29 (2013)

2. E.A. Karpova, Je.M. Ali, G. Skripkjunas, Ja. Kerene, A. Kichajte, G.I. Jakovlev, M. Macijauskas, I.A. Pudov, Je.V. Aliev, S.A. Senkov, Stroitel'nye materialy 2, 40-48 (2015)

3. S. Petrunin, V. Vaganov, K Sobolev, Journal of the Society for American Music 2, 1611 (2014)

4. G. Yakovlev, G. Pervushin, I. Maeva, I. Pudov, A. Shaybadullina, J. Keriene, A. Buryanov, A. Korzhenko, S Senkov, Procedia Engineering, Modern Building Materials, Structures and Techniques, 407-413 (2013)

5. G.I. Jakovlev, G.N. Pervushin, Ja. Kerene, I.S. Poljanskih, I.A. Pudov, D.R. Hazeev, S.A. Senkov, Stroitel'nye materialy 1-2, 3-7 (2014)

6. S.Ju. Shehovcova, M.A. Vysockaja, Vesting MGSU 11, 110-119 (2015)

7. B. Wang, Y. Han, S. Liu, Construction and Building Materials 46, 8-12 (2013)

8. M. Konsta-Gdoutos, Z.S. Metaxa, S.P. Shah, Cement and Concrete Research 40, 10521059 (2010)

9. A. Yazdanbakhsh, Z. Grasley, B. Tyson, Al-Rub R. Abu, Trans. Res. Rec. 1, 95-98 (2010)

10. A. Sirotkina, E. Fedorovich, V. Sergeev, Psychology of Learning and Motivation Advances in Research and Theory 67, 101-106 (2017), doi:10.1016/j.jppr.2017.01.007

11. S.V. Samchenko, O.V. Zemskova, I.V. Kozlova, Russian Journal of Applied Chemistry 87(12), $1872-1876$ (2014)

12. J. Rausch, R.C. Zhuang, E. Moder, Composites A. 41, 1038-1046 (2010)

13. O. Mendoza, G. Sierra, J.I. Tobon, Construction and Building Materials 47, 771-778 (2013)

14. S.V. Samchenko, O.V. Zemskova, I.V. Kozlova, TTS 21, 14-18 (2014)

15. B. Ruan, A.M. Jacobi, Nanoscale Research Letters 7, 127 (2012)

16. E.V. Korolev, M.I. Kuvshinova, Stroitel'nye materialy 9, 85 - 88 (2010)

17. E.V. Korolev, A.S. Inozemcev, Stroitel'nye materialy 1, 1 - 4 (2012)

18. V.I. Roldugin, Colloid Journal 77(2), 214-219 (2015)

19. A.A. Sobolev, Colloid Journal 77(3), 364-377 (2015)

20. E.A. Zaharychev, M.A. Kabina, E.N. Razov, L.L. Semenycheva, Colloid Journal 78(5), 556-561 (2016)

21. V.N. Celujkin, Colloid Journal 78(5), 668-670 (2016) 